\title{
Factors Influencing Condom usage among Male to Female Transgender in Chennai City
}

\author{
M. Sudha ${ }^{1}$, L. S. Suga Priyanka ${ }^{2}$, P. Padmanaban ${ }^{3}$ \\ ${ }^{1}$ Assistant Professor, Department of Social Work, Mar Gregorios College, Chennai \\ ${ }^{2}$ Assistant Professor, Department of Social Work, Mar Gregorios College, Chennai \\ ${ }^{3}$ Assistant Professor, Department of Social Work, Mar Gregorios College, Chennai
}

\begin{abstract}
Male to Female Transgender experience economic vulnerability, lack of employment opportunities, social exclusion gender - based violence and abuse. This makes them vulnerable to be one of group that are affected by HIV epidemic. Lack of education and employment forces them to take up sex work and evidence indicate that $90 \%$ of Male to Female Transgender in India are involved in sex work and thus makes the vulnerable to HIV infection. This made it very essential to study the condom usage patter and also the factors that influence the usage. Objective: Study the condom usage patter and also the factors that influence condom usage. Methodology: In June 2016, 784 Male to Female Transgender enrolled in the CBO - Thozhi, 275 in Transgender Rights Association (TRA) and 282 in Tamil Nadu Aravanigal Association (THAA). A sample size of 299 was taken. As mixed method was used in depth interviews (9) and three focus group discussion (6 respondents in each group) was conducted to collect data qualitative data. Finding: One fourth (25\%) of the respondents were living alone while nearly one fifth (18\%) of the respondents lived with their male sex partners. More than one forth (28\%) had sex work as their primary occupation while one third (34\%) of them had it as their secondary occupation. Out of 120 respondents who were involved in sex work only forty percent were using consistently and of the 134 respondents who had permanent male partners only forty percent of them used condoms consistently. Need for more money (69\%), influence of alcohol (63\%), Unwilling to use by law enforcers \& anti-socialists (24\%), for sexual pleasure (74\%) and with good looking clients (54\%). For respondents who had permanent partners, love/scared of getting disserted/inability to use with husband was some of the responses expressed by the respondents.
\end{abstract}

Keywords: Condom, Transgender, India

\section{Introduction}

Transgender people's immediatentediviteisk iłIV risk is relatedprimarily to sexual behaviours, especially unprotected analsex with an HIV positive partner. The current national average HIV prevalence among Male to Female transgender people is estimated at $8.8 \%$, more than 20 times the general population's average HIV prevalence $(0.4 \%)$ ( Ammulall respontt, 2011)

There is limited data on sexual risk behaviors of HIVpositive Male to Female Transgender. In a study among HIV positive Male to Female Transgender (Chennai and Mumbai), the prevalence of inconsistent condom use during receptive anal sex was $34 \%$ for male regular partners and $41 \%$ for male casual partners (Chakrapani.V et al, 2013). Even though two-fifths of male to female transgender participants in that study reported having disclosed their HIV status to their male regular partner, disclosure was not uniformly followed by safer sex, and non-disclosure did not always lead to unprotected sex.

\section{Methodology}

In June 2016, 784 Male to Female Transgender enrolled in the CBO - Thozhi, 275 in Transgender Rights Association (TRA) and 282 in Tamil Nadu Aravanigal Association (THAA). A sample size of 299 was taken. As mixed method was used in depth interviews (9) and three focus group discussion (6 respondents in each group) was conducted to collect data qualitative data. A Semi structured interview schedule was used to collect data. SPSS was used to analyse the data.

After administering the informed consent, the IDIs and FGDs were conducted in vernacular language. IDIs and FGDs were tape recorded and were transcribed and translated. Codes were derived and thematic content analysis and constant comparative techniques were used to analyse the data.

\section{Finding}

Most of the respondents (89\%) had exposure to formal education.

One fourth $(25 \%)$ of the respondents were living alone while nearly one fifth $(18 \%)$ of the respondents lived with their male sex partners. Only $12 \%$ of the respondents lived with their parents.

\section{Occupation}

More than one fourth (28\%) had sex work as their primary occupation while one third (34\%) of them had it as their secondary occupation. 


\section{International Journal of Science and Research (IJSR) \\ ISSN (Online): 2319-7064}

Index Copernicus Value (2015): 78.96 | Impact Factor (2015): 6.391

Respondent - ID- 9: "Neither we are allowed to study nor u gives us work ..... they what else can we do .....? ?

Respondent - ID- 7: "Men mock at as and women are scared to employ us... I don't want to beg this is better for me."

\section{Condom Usage}

Out of 120 respondents who were involved in sex work only forty percent were using consistently and of the 134 respondents who had permanent male partners only forty percent of them used condoms consistently.

\section{Factors that influence Condom Usage}

Need for more money (69\%), influence of alcohol (63\%), Unwilling to use by law enforcers \& anti-socialists (24\%), for sexual pleasure $(74 \%)$ and with good looking clients $(54 \%)$.

\section{Quotes from respondents}
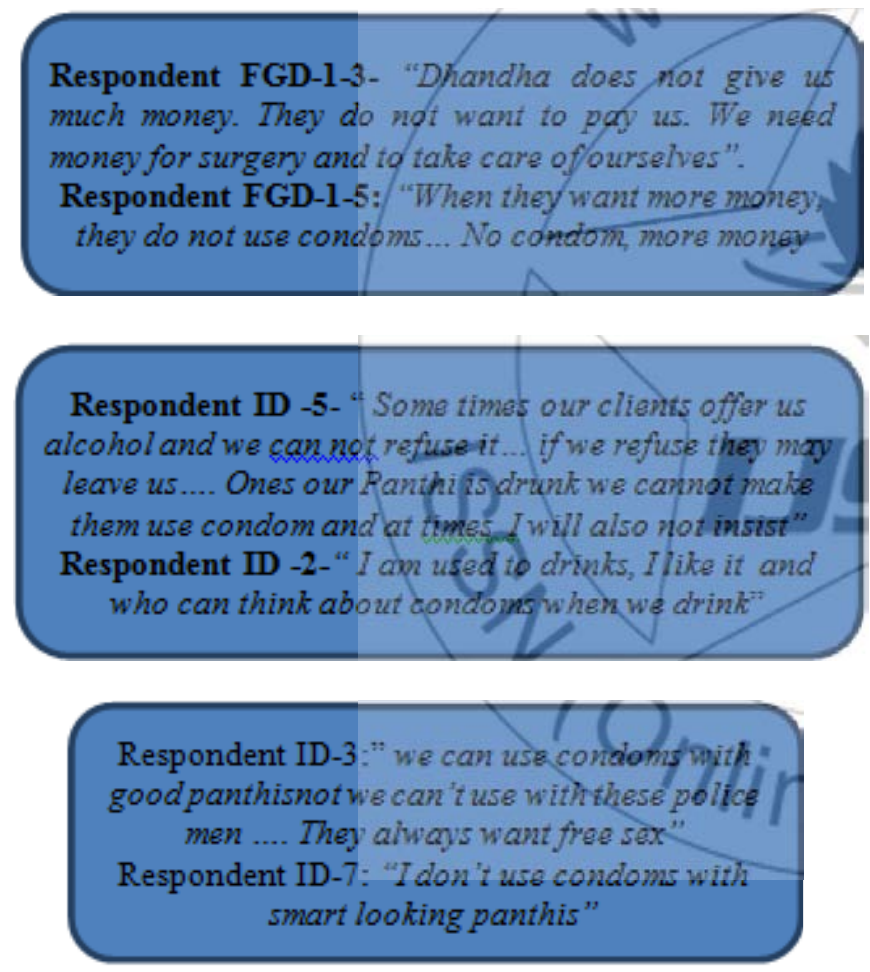

For respondents who had permanent partners (134), fifty two of them expressed that they loved their partners, seventy six of them shared that they are that using of condoms may upset their partners and they may disserted them and fifty of them felt they can't use condoms with their husbands.

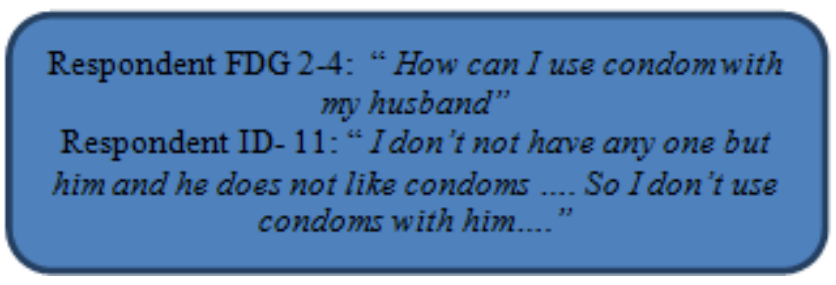

\section{Discussion}

A study from Chennai documented $68 \%$ alcohol use among aravanis in Chennai and $22 \%$ of them consumed alcohol daily (Saravanamurthy.P.S, et al 2010). Also, that study found that alcohol use was more strongly associated with multiple casual and paid partners than with long-term partners. Also, 29\% reported sex under the influence of alcohol, which was often associated with unsafe sex.

Finding in the current study portrays a higher percent of respondent. A survey in urban and rural sites in Maharashtra and Tamil Nadu reported that among those who did not use condom in the last anal sex $(27 \%), 62 \%$ reported having consumed alcohol before sex Shanmugam.M, et al, 2011). This finding is similar to the finding of the current study.

Studies among transgender women in the USA and Asiaindicate that they commonly practise unprotected receptiveanal intercourse (Barrosb A, et al, 2008) Transmission of HIV is 18 timesmore likely to occur through unprotected receptive anal sexthan through unprotected vaginal intercourse (Baggaley R.F, 2010). In Chiang Mai, Thailand, a survey of transgender people attending a voluntary counselling and testing centre found that three-quarters of them had practised unprotected anal intercourse with a regular partner in the previous six months, while $55 \%$ had done so with a casual partner. (Chariyalertsak.S et al, 2011) Transgender women may engage in receptive rather than insertive sex in order to affirm their feminine identity. (Edwards, J. W. et al, 20007) Like other people, some transgender women consider unprotected sex a way to demonstrate trust in their partner, even if they do not know their partner's HIV status.(Policy Brief, Thailand , 2013)

In studies conducted in Los Angeles and Chicago, USA, over $90 \%$ of transgender participants aged 15-24 years had used alcohol or drugs during their lifetimes (Wilson E.C et al, 2009) In the Chicago study, 57\% of transgender women aged 16-25 years reported having sex under the influence of drugs or alcohol, and this was significantly associated with both unprotected anal intercourse, and with selling of sex. Young transgender people in relationships, like nontransgender people, may use condoms less frequently with their main partners than with casual or commercial partners. A study in Los Angeles and Chicago, USA, found that young transgender women who sell sex were less than one-third as likely to use a condom during receptive anal intercourse with their main partner as with commercial partners.(Wilson, E.C et al, 2010) In Thailand, $61.0 \%$ of transgender people reported inconsistent condom use with their steady partners, and $32.7 \%$ with their casual partners.( Guadamuz, T.E.,et al , 2011)

\section{References}

[1] Barrosb ASchulden JD \&Song B, (2008).Rapid HIV testing in transgender communities by communitybasedorganizations in three cities. Public Health Reports; 123:101-114

[2] Baggaley RF, White RG \&Boily M-C., (2010) Aug;39(4),HIV transmission risk through anal 


\section{International Journal of Science and Research (IJSR) \\ ISSN (Online): 2319-7064}

Index Copernicus Value (2015): 78.96 | Impact Factor (2015): 6.391

intercourse: systematic review, metaanalysis and implications for HIV prevention. International Journal of Epidemiology:1048-63..

[3] Chariyalertsak S, Kosachunhanan N, Saokhieo P, Songsupa R \&Wongthanee A,(2011).HIV incidence, risk factors, and motivation for biomedical intervention among gay, bisexual men, and transgender persons in Northern Thailand. PLoS ONE;6(9):e24295

[4] Edwards, J. W., Fisher, D. G., \& Reynolds, G. L.(2007)Male-to-female transgender and transsexual clients of HIV service programs in Los Angeles County, California. Am J Public Health.97(6):1030-3

[5] Policy brief: 2013, Self-stigma among young men who have sex with men and transgender women and the linkageswith HIV in Asia. Bangkok: Youth Voices Count,

[6] Wilson EC, Garofalo R, Harris RD, Herrick A, Martinez M, Martinez J \&Belzer M(2009).Transgender Advisory Committee, Adolescent Medicine Trials Network for HIV/AIDS Interventions. Transgender female youth and sex work: HIV risk and a comparison of life factors related to engagement in sex work. AIDS and Behavior; 13(5):902-913

[7] Wilson EC, Garofalo R, Harris R, \&Belzer M, (2010).The Transgender Advisory Committee, and the Adolescent Medicine Trials Network for HIV/AIDS Interventions. Sexual Risk Taking Among Transgender Male-to-Female Youths With Different Partner Types. American Journal of Public Health; 100(8):1500,1505

[8] Guadamuz, T. E., Wimonsate, W., Varangrat, A., Phanuphak, P., Jommaroeng, R., McNicholl, J. M., \& Van Griensven, F. (2011). HIV prevalence, risk behavior, hormone use and surgical history among transgender persons in Thailand. AIDS and Behavior, 15(3), 650-658.

[9] Department of AIDS Control, Ministry of Health \& Family Welfare (2013). Annual Report 2012-13. New Delhi: Department of AIDS Control.

[10] Chakrapani, V., Logie, C. H., Shunmugam, M., \& Newman, P.A. (2013, November).Assessment of 'Transgender identity stigma' scale among Indian maleto-female transgender people.E-poster presentation at the 11th International Congress on AIDS in Asia and the Pacific, Bangkok, Thailand.

[11] P. S. Saravanamurthy, P. R., Priya M. Miranda, G. Ashok, Sai S. Raghavan, Julia H. Arnsten, L. Ramakrishnan and S. Vijayakumar. (2010). A Crosssectional Study of Sexual Practices, Sexually Transmitted Infections and Human Immunodeficiency Virus among Male-to-Female Transgender People. American Medical Journal, 1(2), 113-119. doi: 10.3844/amjsp.2010.113.119

[12] Shunmugam, M., Sivasubramanian, M., Roy Karmakar, S., Samuel, M., \&Chakrapani, V. (2012, July). Extent of alcohol use and its association with inconsistent condom use among hijras/transgender (male-to-female) people in India: survey findings from urban and rural sites in Maharashtra and Tamil Nadu. Poster presented at the International AIDS Conference, Washington DC, USA. 